Humberto Hernández Hernández

Universidad de La Laguna

\title{
ASPECTOS ORTOGRÁFICOS Y ORTOLÓGICOS RELACIONADOS CON LOS EXTRANJERISMOS EN LA ENSEÑANZA DEL ESPAÑOL COMO LENGUA EXTRANJERA
}

\section{Sobre el concepto de extranjerismo}

No han sido muchas las ocasiones en que se han afrontado los problemas que pueden plantearse con la enseñanza de las unidades léxicas consideradas extranjerismos en la clase de español como lengua no materna, acaso, porque no se la considerase una cuestión que entrañe suficiente interés o, porque al hacerlo, podrían aparecer nuevos problemas que se sumarían a la ya compleja labor docente: téngase en cuenta que en estos casos el estudiante extranjero ha de aprender una unidad extranjera a través de un sistema linguiístico que también es extranjero. Pero la dificultad no sería tanta si diéramos al concepto de extranjerismo su justo valor: «voz, frase o giro que un idioma toma de otro extranjero» (así lo define el DRAE): sería, pues, extranjerismo lo foráneo sincrónicamente arraigado, y no cualquier elemento de otra lengua que se presente de forma repentina y excepcional. El extranjerismo es, por tanto, una unidad integrada en el idioma, aunque a veces puede presentar caracteres formales que delatan su procedencia.

El extranjerismo es un tipo de neologismo ya que se trata de una «voz que no ha sido empleada antes en la lengua», como lo entiende M. Alvar Ezquerra (1994), o, como se define en el Diccionario de Lingüística de J. Dubois (s.v.), es una «Palabra de creación reciente o recientemente tomada de otra lengua [...]». El concepto de extranjerismo puede ser coincidente con el de préstamo, aunque suele identicarse sobre todo con uno de sus tipos, el xenismo, que es el extranjerismo que conserva su grafía original. También, desde otra perspectiva, coincide con el denominado barbarismo, que se define como el «extranjerismo no incorporado tortalmente en el idioma» ${ }^{1}$.

Conceptos, como vemos, un tanto inexactos, como impreciso es el mismo concepto de neologismo. Así lo señala Julio Fernández-Sevilla (1982: 13):

El concepto de neologismo se resiste a ser precisado con criterios objetivos. Aparte de que resulte muy difícil -la mayoría de las veces imposible- documentar el alumbramiento de una palabra, más difícil aún resulta precisar en qué momento lo que era neológico deja de serlo por haberse integrado en la masa de elementos patrimoniales del idioma.

Y propone, a continuación, algunos criterios que pueden ayudar a determinar cuándo una palabra es un neologismo o cuándo pasa a dejar de serlo:

[...] si se trata de una voz de origen extranjero, su total adaptación fonética y gráfica al sistema de la lengua que la recibe constituye la mejor garantía de que ha perdido ya el carácter neológico. Desde el punto de vista morfosintáctico, el neologismo se ha adaptado a la lengua -y en consecuencia ha perdido su carácter de tal- cuando sirve de base para la formación de derivados: el anglicismo gol ha dado lugar en español contemporáneo a golear, goleada, golazo, etc., formados según las usuales reglas de derivación. Por último,

\footnotetext{
1 Son definiciones tomadas del DRAE.
} 
desde el punto de vista semántico, puede considerarse adaptado el neologismo que desarrolla nuevos sentidos y se vuelve polisémico (pp. 13-14).

Para no entrar en más disquisiciones terminológicas, vamos a considerar extranjerismo a lo que suele reconocerse como xenismo: voz del español que formalmente se aleja de lo que es normal ortográfica u ortológicamente.

Y, como sé que cualquier discusión que se plantee en torno a estas cuestiones tendrá que relacionarse con el concepto de norma, comparto con Luis Fernando Lara (1976:110) la idea de que ésta es «un modelo, una regla o un conjunto de reglas con cierto grado de obligatoriedad, impuesta por la comunidad lingüística sobre los hablantes de una lengua, que actúa sobre las modalidades de actualización de su sistema lingüístico, seleccionando de entre la ilimitada variedad de posibles realizaciones en el uso, aquellos que considera aceptables».

Un concepto lingüístico y democrático porque consideraría ajustado a ella todo aquello que la comunidad acepta como tal, y no «porque lo decreten unos individuos -los miembros de la Academia- refrendados por un consenso corporativo no siempre unánime», según opinión de Emilio Lorenzo (1995).

Confío, por otra parte, como quiera que la finalidad de este estudio es la de proporcionar orientaciones normativas, en que no se me juzgue como purista, actitud que no considero defendible desde la perspectiva científica: todas las lenguas son, en mayor o menor medida, mestizas, y el español también lo fue desde su configuración inicial. Al respecto afirma F. Lázaro (1997: 285):

No existe ninguna lengua pura: todas desde sus orígenes, son productos de mestizaje.

La impureza es lo que permite que las lenguas sean instrumentos adecuados a las cam-

biantes y progresivamente complejas necesidades de sus usuarios.

Palabras que comparto plenamente, y este acuerdo me exime de mayores argumentaciones a favor de mi postura.

La llegada de extranjerismos no es un hecho nuevo en la historia de las lenguas, ni debe entenderse como un fenómeno negativo con capacidad para adulterar su original naturaleza; si bien, reconocer la evidencia del secular intercambio lingüístico no debe ser un pretexto para justificar la laxitud y la anarquía que a veces observamos y que podría conducir a una indeseada fragmentación: «[...] el mestizaje, que refuerza el hecho lingüístico tanto como el biológico - afirma el periodista Carlos Luis Álvarez «Cándido»-, puede deslizarse hacia la amalgama más que hacia la aleación. No soy un racista de la lengua -concluye-, sino un miedoso de la jerigonza ${ }^{2}$

$\mathrm{Y}$, a veces, son razonables los temores, porque se encuentra uno con enunciados plagados de injustificadas voces foráneas, con pronunciaciones extrañas también, cuando los mensajes son orales, que delatan lo anómalo (lo alejado de la norma que nos hemos impuesto) de un buen número de discursos: slamning 'preasignación irregular', facility management 'sector que se ocupa de la limpieza y mantenimiento de edificios', bloggers 'página o portal personal', park and rider 'aparcamiento disuasorio', profit warning 'aviso sobre beneficios', handling 'labores de asistencia en tierra a los pasajeros y compañías aéreas', y finger 'pasarela en los aeropuertos' son algunos de los detectados por un colega en las páginas del diario El País de un solo día.

2 Tomado del artículo «De la lengua española», por el que se le concedió el Premio Miguel Delibes de la Asociación de Periodistas de Valladolid. 
En casi todos estos casos los extranjerismos no eran necesarios, pero ocurre que para muchos el uso de las palabras foráneas, inglesas sobre todo, es una cuestión de prestigio. Como se observa en la preferencia por la denominación de ciertas actividades deportivas aun poseyendo un correlato exacto en español: trekking por senderismo, rafting, en vez de descenso en balsa, climbing por escalada. Preferencia tan fuerte por lo anglicado que ha dado lugar a la aparición de palabras-fantasma, como footing, que es un invento francés (en inglés el ejercicio que consiste en correr de manera moderada y constante se denomina jogging), canyoning, el equivalente a barranquismo, o puenting, que designa a la actividad que consiste en lanzarse al vacío desde un puente sujeto por una cuerda (Cfr. $\mathrm{M}^{\mathrm{a}}$ Victoria Escandell, s.f.).

Tenemos ya una primera conclusión que se extraería de lo que venimos diciendo, y es que el profesor de español como lengua extranjera debe contribuir a erradicar esta forma de proceder -prejuicios en los nativos- que en nada contribuyen al mejor conocimiento y adecuado uso de nuestro idioma.

No suelen planteársele problemas al hablante nativo ordinario en el uso diario y espontáneo de la lengua, pero sí aparecen dudas y dificultades cuando como profesores o aprendices nos enfrentamos ante estos elementos lingüísticos que, observados desde la reflexiva distancia del estudioso y del estudiante extranjero, constituyen anomalías que se revelan como inadecuaciones a las situaciones comunicativas estándares.

Hechas estas iniciales consideraciones, podemos pasar ya al objetivo central de esta comunicación: algunos problemas que plantean los extranjerismos en la enseñanza del español como lengua extranjera.

En primer lugar nos vamos a centrar en lo relacionado con el estatus de los extranjerismos, circunstancia que nos dará las claves para decidir acerca de la conveniencia de su enseñanza y sobre aspectos relacionados con su escritura.

\section{Aspectos metodológicos relacionados con la ortografía}

Es posible encontrar en algunos diccionarios orientaciones normativas acerca de los extranjerismos -sobre su escritura y su pronunciación-. En el DRAE se registran en letra redonda negrita, como la mayoría de las voces de su nomenclatura, los extranjerismos cuya escritura o pronunciación se ajustan a los usos del español. Son casos como los de club, réflex y airbag -pronunciadas como se escriben-; ahora bien, si su escritura o su pronunciación son ajenas a las convenciones de nuestra lengua (pizza o blues) figuran en letra cursiva (Vid. el capítulo «Advertencias para el uso de este diccionario», el apartado 2.5 (Extranjerismos).

Siguiendo el principio de adecuación a la pronunciación que había prevalecido en la ortografía española, la Academia se había ocupado de adaptar los extranjerismos que se iban incorporando; sin embargo, en los últimos años y debido, como decíamos, a la avalancha anglicista sobre todo, no se ha producido la adaptación con la oportunidad deseada. Es posible que sea ésta la razón por la que la Academia, incapaz de mantener el ritmo que exigía la adaptación o ante el riesgo de ser criticada de excesivamente innovadora ${ }^{3}$ se ha

\footnotetext{
3 En el artículo de Juan Carlos Arce, «La Academia», publicado en La Razón Digital, se afirma: «[...] la Real Academia Española, metida en modas, ha tomado del inglés unos neologismos estridentes, los ha pasado por la ortografía castellana, ha parido dos novísimas palabras sin dolor alguno y ha clonado el yin y el bluyín. Éste es el día en que no salgo todavía de mi asombro». Y dice más adelante: «Hay que estar mal de fondos propios en el diccionario para importar palabras tan feas y tan absurdas».
} 
visto en la tesitura de tener que rechazar extranjerismos extendidos o tener que incorporarlos en la forma de su originaria procedencia.

Algunas de las adaptaciones de voces cuya ortografía se alejaba de la pronunciación son las siguientes ${ }^{4}$ :

banyo (<ing. banjo) [Pero también mantiene banjo, donde define]

beicon (<ing. bacon) [También bacón, donde define]

beis $(<\text { fr. beige) [Pero mantiene beige en cursiva }]^{5}$

bumerán (<ing. boomerang)

buqué (<fr. bouquet)

chovinismo ( $<$ fr. chauvinisme) [Pero mantiene chauvinismo, desde donde remite]

chovinista [pero mantiene chauvinista, desde donde remite]

clon (<ing. clown) [aquí define sinonímicamente, payaso, pero en clown, en cursiva, define sin remisión y de forma diferenciada: «m. Payaso de circo, y especialmente el que, con aires de afectación y seriedad, forma pareja con el augusto».]

cruasán $(<$ fr. croissant)

cupé $(<\mathrm{fr}$. coupé)

güisqui (<ing. whisky) [pero mantiene whisky, en cursiva, desde donde remite]

magacín / magazín (<fr. magasin a trav. del ing. magazine)

nailon (<ing. nylon) [pero mantiene nilón, desde donde remite]

pedigrí (<ing. pedigree)

vermú o vermut (<al. wermuth)

yogur (<turco yogurt)

yóquey o yoqui (<ing. jockey)

yudo (<jap. yudo) [pero mantiene judo, desde donde remite]

yudoca

zum (<ing. zoom)

${ }^{4}$ Hay ocasiones en que se realiza una adaptación ortográfica pero que no influye en los aspectos ortológicos, el hecho es que los criterios son variados:

a) No se respeta la ortografía originaria y se procede a la adaptación ortográfica, como por ejemplo

«maltusianismo. m. Conjunto de las teorías económicas de Malthus [...]». [En la adaptación ha desaparecido la $h$ del nombre propio originario].

b) Se respeta la ortografía originaria, como en el siguiente caso:

«goethiano [también goetheano, desde donde remite a goethiano]. Perteneciente o relativo a Johann Wolfgang Goethe o a su obra. [...]». [En este caso se mantiene la $h$ del nombre propio originario].

Téngase en cuenta que en esta edición del DRAE figuran en letra cursiva los extranjerismos cuya «representación gráfica o su pronunciación son ajenas a las convenciones de nuestra lengua, como es el caso de rock, pizza o blues -pronunciado generalmente este último como [blus]-. Los derivados españoles de palabras extranjeras, aunque estas presenten dificultades gráficas o de pronunciación, se representan en letra redonda. P. ej., pizzería, flaubertiano» (Cfr. DRAE, «Advertencias para el uso de este diccionario», 2.5., pp. XXX-XXXI). 
Incorpora, además, poco más de dos centenares de voces que, posiblemente por las razones aducidas anteriormente, no han sido adaptadas: adagio, affaire, alzheimer, apartheid, baby-sitter, ballet, best seller, big bang, blazer, blues, body, boiserie, boîte, boom, bourbon son los extranjerismos en cursiva que encontramos en las letras $a$ y $b$ del Diccionario académico.

Sin embargo, en esta $22^{\mathrm{a}}$ edición del DRAE, la Academia, no sabemos por qué razones, suprime algunas de las viejas adaptaciones. Así, por ejemplo, se elimina pimpón, pero mantiene ping-pong en cursiva, y tur $(<$ de tour), aunque continúa la forma tour, en cursiva. También ha desaparecido yaz, aunque mantiene jazz, en cursiva. Otras como beige y whisky, lo mismo que ballet, boutique y best-séller, han sido devueltas a su condición de voces extranjeras no incorporadas plenamente en el idioma y aparecen ahora en letra cursiva $^{6}$ : ballet, beige, whisky, boutique, best seller.

Se plantean con estos extranjerismos en cursiva problemas ortográficos de interés didáctico, pues no sabemos con certeza a qué atenernos cuando tenemos que escribirlos: ¿entrecomillados?, ¿en cursiva?, ¿subrayados?, muchos de ellos de uso frecuente y con algunos años ya en la vida del idioma.

Problemas de otra índole de inadecuación a las normas ortográficas los presentan extranjerismos como boîte y maître, con acentos -los circunflejos-inexistentes en español, o palabras que deberían llevar tilde según las normas de acentuación y aparecen sin ella (cricket, holding, hobby).

Fernando Lázaro, consciente de la inconsistencia de esta decisión académica, aun reconociendo que estos extranjerismos tienen su presencia justificada en el repertorio académico, proponía que se sacaran del cuerpo central del Diccionario y se elaborara una lista de extranjerismos que sólo tuviera su límite en las nomenclaturas técnicas de empleo restringido.

\section{Los extranjerismos y la ortología}

Mayores dudas surgen cuando nos ocupamos de los aspectos fonéticos que atañen a los extranjerismos. Téngase en cuenta que es el fónico, probablemente, el nivel lingüístico que más se valora cuando se desea comprobar el grado de conocimiento de una segunda lengua; tanto, que su dominio puede incluso llegar a identificarse con el dominio de la lengua en su totalidad. Si un extranjero utiliza sonidos reconocidos como prototípicos y hace un uso relativamente fluido de la lengua, puede pasar por un hablante competente, por deficiente que sean los aspectos morfosintácticos y los léxico-semánticos.

Ilustrativo en este sentido es el Pigmalión de Bernard Shaw. Encontramos una lección magnífica de la importancia de la ortología: « $i$ Ve usted a esta criatura con su lenguaje canallesco y su infernal prosodia, que no la dejarán salir del arroyo en toda su vida? Pues bien: en tres meses yo podría hacerla pasar por una duquesa en la recepción o la garden party de cualquier embajada», le decía el fonetista Henry Higgins al coronel Pickering, a propósito de la joven florista Elizabeth Doolittle. Pero también, en la misma obra, se observan claras advertencias de que el aspecto fónico no lo es todo, y, así, tras los reproches de su mujer al enterarse de que la había invitado a su casa en un día de recibo, él la tranquiliza con el siguiente argumento: «No te asustes; no hará ningún estropicio. Yo la he enseñado a hablar con propiedad y a portarse perfectamente. Le he recomendado que no

6 Por lo dicho en la nota anterior. 
hable más que de dos cosas: del tiempo y de la salud, de ese modo vago y general como se suele hablar en sociedad».

En el aprendizaje de una lengua, materna o extranjera, son fundamentales también, por supuesto, los planos morfosintáctico y léxico-semántico.

No disponemos de muchas obras de consulta que nos orienten sobre estas cuestiones. Si acudimos, por ejemplo, al Diccionario académico en busca de recomendaciones normativas, nos sorprenderá la ausencia de notas ortológicas; observaremos que han desaparecido algunas de las que se ofrecían en la edición anterior, como las de blues [Se pronuncia aprox. /blus/], boutique [Se pronuncia aprox. /butík/], freudiano [En esta voz el diptongo eu se pronuncia oi], hachís [A veces se aspira la $h$ ], hegeliano [En esta voz se aspira la $h$, y la $g$ tiene sonido suave]), y es ésta una deficiencia que hay que hacer notar.

Las únicas orientaciones sobre la pronunciación que proporciona la vigésima segunda edición del DRAE (aparte de la que figura en las entradas de ciertas grafías, como en b, j, ll y z) son las que pueden extraerse del capítulo de «Advertencias» (apartado 2.5., Extranjerismos), que ya hemos comentado.

Escuetas orientaciones de escasa utilidad, pues nada nos dice sobre la pronunciación de los xenismos -los extranjerismos que en el DRAE aparecen en cursiva-, y muy poco podríamos deducir de los casos de extranjerismos con doble grafía e idéntico estatus (con letra redonda en el diccionario), como no sea que se trata de palabras con doble posibilidad ortológica también: banjo / banyo, chovinismo / chauvinismo, chovinista / chauvinista, nailon / nilón, yudo / judo.

\section{Algunas propuestas}

Con el fin de proporcionar unas orientaciones ortológicas básicas relacionadas con los extranjerismos, vamos a realizar una primera clasificación de tales voces, considerando los que registra el DRAE, atendiendo a su pronunciación normal, la comúnmente aceptada:

a) Nos encontramos, por una parte, con un grupo de extranjerismos cuya pronunciación generalizada se adecua a la tendencia de igualdad fonográfica que es tradicional en español. Ejemplos de estos serían, entre otros, bulldozer, bungalow, clown, cricket, curry, cyclo-cross, ketchup, punk, rugby.

b) Hay, por otro lado, extranjerismos con pronunciación que se aleja de la escritura pero con cierto grado de adaptación y de fijeza; así, en un sentido estricto, no pueden considerarse las pronunciaciones, más o menos estables, [afér], [bléiser], [buaserí], [kolaĉ], [yentelmán], [métre], [oberbúkin], o [partenér] como exactas representaciones fónicas de las pronunciaciones, en sus respectivas lenguas, de las palabras affaire, blazer, boiserie, collage, gentleman, maître, overbooking y partenaire.

La ausencia de normas que fijen estas tendencias generalizadas ha dado lugar a que se produzcan frecuentes casos de inadecuación, como he constatado en unas encuestas realizadas a un centenar de profesores extranjeros de español como lengua extranjera. Los tipos más frecuentes de pronunciaciones anómalas fueron los siguientes:

1) Pronunciar los extranjerismos de acuerdo con los principios de correspondencia grafía $\rightarrow$ sonido del español: [afáire], [blazér], [boiseríe], [kolláxe], [géntleman], [máitre], [oberboókin] y [partenáire], 
2) El otro tipo es el de tratar de pronunciar, sobre todo cuando se poseen conocimientos lingüísticos suficientes, del modo en que se hace en las lenguas de procedencia. El híbrido resultado se aleja de la norma, pues se mezclan sistemas fonológicos distintos, y las pronunciaciones se perciben como artificiosas o afectadas. Las simples pronunciaciones [bángalou], [klaun], [kríkit], [kári], [sáikl,kros], [kétĉap], [pank], [rágbi] para las voces bulldozer, bungalow, clown, cricket, curry, cyclo-cross, ketchup, punk, rugby supondrían un distanciamiento de la norma ortológica establecida por el uso.

Más desajustes se producen cuando aparecen otros rasgos fónicos ajenos a nuestro idioma: vocales anteriores labializadas, consonantes vibrantes velares, o algunos tipos de palatales [como la y de la palabra gin o la s de fashion]: boiserie, partenaire, gentleman, fashion.

Parece que es el sonido palatal sordo [J] (el de fashion, short, show, sherpa) el que menos alejado se siente de nuestra normal ortología (como tampoco se siente la realización aspirada de la velar fricativa sorda: [húligan] (pronunciación de hooligan); tal vez, porque son elementos fónicos presentes en algunas variedades del español no estándar:

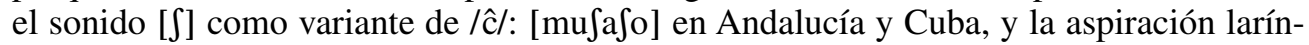
gea [h] como variante de /x / o de /s / en posición implosiva.

Curiosamente, la doble posibilidad de realización del dígrafo inglés sh (como $\int$ o ĉ) se aprovecha, en la lengua de los jóvenes, con finalidad distintiva o estilística: «El diseño tiene un inconfundible toque fashion [fáfon]» ('de última moda')», pero «Qué fashion [fáĉon] estás hecha», en este caso con el valor de 'pija, que ostenta de forma afectada una buena posición social'. O como en estos otros ejemplos: «Fue un magnífico show [Sou]» ('espectáculo')», frente a «Menudo show [ĉou] ('número') que estás montando».

\section{Final}

Puede resultar sorprendente, pero, frente a los esfuerzos normalizadores que podamos hacer desde las aulas (o desde algunas instituciones), nos encontramos con la resistencia de la ignorancia y la desidia. Un errado criterio de corrección y prestigio lingüísticos lleva a muchos hablantes a decantarse por lo extranjero como única posibilidad de exhibir una capacidad idiomática que no se posee. Así se explica que existiendo la forma adaptada buqué (ya en DRAE desde la $20^{\mathrm{a}}$ edición de 1984) para el extranjerismo bouquet, que no aparece en el diccionario académico, se prefiera este último, como lo demuestran los registros del CREA: 67 casos de bouquet frenta a 9 de la forma adaptada buqué; o los 1838 casos que se registran para la forma whisky (en cursiva en DRAE), frenta a los 118 de güisqui; los 779 de chalet frente a los 479 de chalé (las dos admitidas), o los 199 de boutique frente a las dos apariciones de la forma adaptada butic, propuesta muy acertada, a mi juicio, que no registran aún los diccionarios pero que sí han utilizado algunos escritores de renombre (Vid. CREA: Corpus de Referencia del Español Actual, en www.rae.es).

Lo peor es que todos estos desajustes se dan también en hablantes nativos, tal vez porque, aunque tarde, han conseguido chapurrear la lengua del Imperio, la que los identifica con el progreso y los aproxima al éxito, aunque sea a costa de renunciar al inmenso patrimonio que le pudo haber supuesto profundizar en la lengua de sus primeros balbuceos.

Es verdad que el conocimiento o la familiaridad con otras lenguas pueden favorecer estas interferencias que se perciben como anomalías ortológicas, aunque, también es cierto que, a mayor conocimiento de la lengua que aprendemos (como primera o como segunda) menos expuestos estaremos a indeseadas influencias de las otras. 


\section{BIBLIOGRAFÍA}

Alvar EzQuerra, M. [dir.] (1994): Diccionario de voces de uso actual. Madrid: Arco/Libros.

Dubois, J. et al. (1979): Diccionario de lingüística. Madrid: Alianza.

ESCANDELl, M ${ }^{a}$ V.: «Footing». En: Palabra por palabra. A pie de página: www.cvc.cervantes.es.

FERNÁNDEZ-SEVILLA, J. (1982): Neología y neologismo en español contemporáneo. Granada: Universidad-Librería Don Quijote.

LARA, L. F. (1976): El concepto de norma lingüística. México: El Colegio de México.

LÁzAro CARreter, F. (1997): El dardo en la palabra. Barcelona: Galaxia Gutenberg / Círculo de Lectores.

LORENZO, E. (1995): «Lo correcto y lo incorrecto». En: $A B C, 8$ de agosto.

Maldonado, C. [dir.] (1999): Clave. Diccionario de uso del español actual, $3^{\mathrm{a}} \mathrm{ed}$. Madrid: Ediciones SM. (Citamos Clave).

Real Academia Española (2001): Diccionario de la lengua española. Madrid: Espasa Calpe. (Citamos DRAE-22 $2^{\mathrm{a}}$.

\section{PRAVOPISNI IN PRAVOREČNI VIDIKI TUJK PRI POUČEVANJU ŠPANŠČINE KOT TUJEGA JEZIKA}

Avtor članka ugotavlja, da se redkokdaj zastavlja vprašanje poučevanja tujih prevzetih besed in/ali besednih zvez pri pouku španščine kot tujega jezika. Učenec, ki mu španščina ni materni jezik, mora usvojiti tujo besedo ali besedno zvezo prek jezikovnega sistema, ki je njemu prav tako tuj, kar mu lahko povzroča težave. Avtor meni, da je tujka oz. prevzeta beseda jezikovna enota, ki se je umestila v jezikovni sistem, nekatere njene značilnosti pa kažejo na naravo prevzete besede. Nekateri slovarji posredujejo navodila za pravilno izgovarjavo in pisavo prevzetih besed $v$ španščini, večinoma pa pravilno pisanje in izgovorjava tujk v španščini nista predmet poučevanja niti proučevanja. Avtor predstavi pravopisne in pravorečne vidike tujk in poda nekaj predlogov in metod za poučevanje pisanja in izgovarjave prevzetih besed pri pouku španščine kot tujega jezika. 